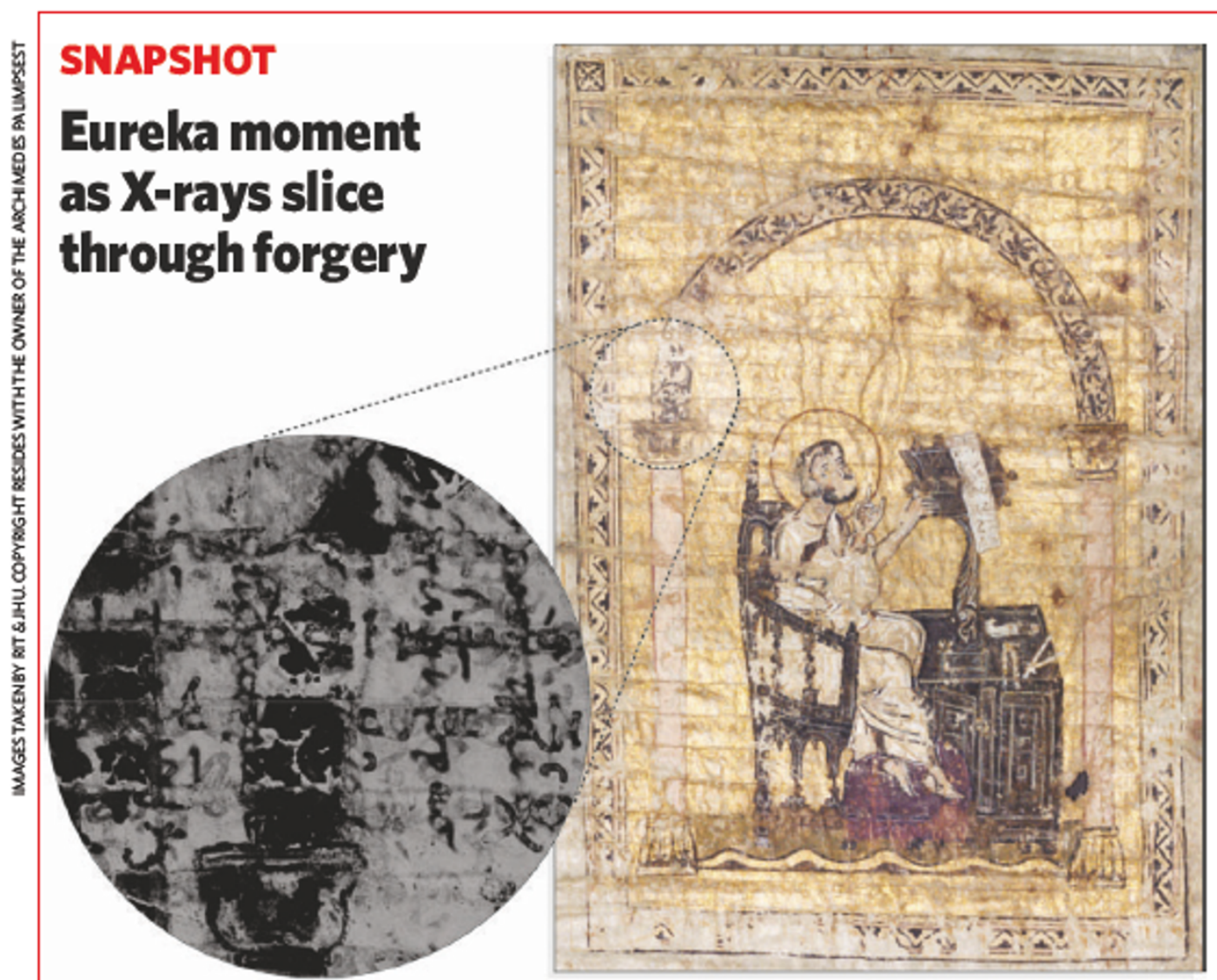

Synchrotron X-rays have been used to reveal long-lost writings from the tenth century.

The Archimedes Palimpsest is the earliest transcription of the theories of the legendary Greek mathematician, and the original text detailed his method of mechanical theorems. In the twelfth century the parchment was scraped clean and reused a common practice to conserve the expensive material. It was turned into a prayer book, but the original writings survive as ghostly outlines beneath the prayers.

They can mostlybe read using ultraviolet light, but some pages are also obscured by twentieth-century forgeries of medieval art (see picture). So researchers at the Stanford Synchrotron Radiation Laboratory in Menlo Park, California, used synchrotron $X$-rays on the piece. These cause the iron in the ink to fluoresce, creating a sharp image (see inset) of the priceless text.

\title{
US aid agency grilled over malaria funds
}

One of the world's largest aid agencies, the US Agency for International Development (USAID), has been hauled before a congressional committee. It faces allegations that its malaria programme is neither financially transparent nor effective. If the agency doesn't start being more open about its spending, it could even see some of its funding being given to other malaria groups.

Congress decided to investigate the agency after an article on malaria spending by Amir Attaran, a law professor at the University of Ottawa, Canada, appeared in Nature (430, 932-933; 2004). A Senate subcommittee heard the results at a hearing on 12 May.

USAID's malaria budget has quadrupled since 1998 to $\$ 90$ million this year. The committee heard that several investigators trying to find out where that money goes had been unable to get firm figures from the agency. Senator Sam Brownback (Republican, Kansas) complained that his requests for detailed spending breakdowns had been met by ${ }^{\alpha}$ ad hoc responses with vague descriptions and math that doesn't add up'. He also accused the agency of using "deceptive rhetoric and distorted science" to defend its actions.

Roger Bate, the US director of Africa Fighting Malaria, a non-profit advocacy group located in South Africa and the United States, presented his best estimates based on the "flawed data ${ }^{*}$ he got from USAID. In 2004, he says, the agency spent just $5 \%$ of its funds on commodities such as bednets, drugs and insecticides, and $13 \%$ on vaccine research. The rest of the money went on other costs such as technical assistance, meetings and consultancy fees.

Michael Miller, deputy assistant administrator for global health at USAID, defended the agency's record. He argued that funding and planning have reached adequate levels only recently. "Any summary judgement of the progress or lack of progress is simply premature, ${ }^{\text {n he said. }}$

Attaran testified that his research suggests USAID malaria funds went mostly on "American consultants, American experts, and very highly paid American 'non-profit' organizations'. But Kent Hill, USAID's acting assistant administrator for global health, told Nature that "USAID prioritizes hiring local staff and consultants", and building local infrastructure.

Brownback told Nature that the US public “deserves nothing less than total transparency". $\mathrm{He}$ has introduced a Senate bill that would require USAID to describe its spending on a public website, and to use half of its budget for purchasing drugs and other commodities.

But Carlos Campbell, who heads MACEPA, an African malaria-control programme, cautioned that Brownback's bill may go too far. Technical assistance is often valuable to countries planning control programmes, he noted. "I ask you to not move everything to commodities, but to keep a balanced view, he said.

In wrapping up, Tom Coburn (Republican, Oklahoma), a physician and chairman of the Senate hearing, pledged to pressure USAID further. "I'm going to find out where every penny is spent, he said. If the agency doesn't cooperate, he warned, malaria funds could be stripped from it and transferred to the Global Fund to Fight AIDS, Tuberculosis and Malaria, an international group set up in 2002.

Declan Butler 